NASA TECHNICAL MEMORANDUM

\section{$N 70 \quad 33056$}

NASA TM X-52855

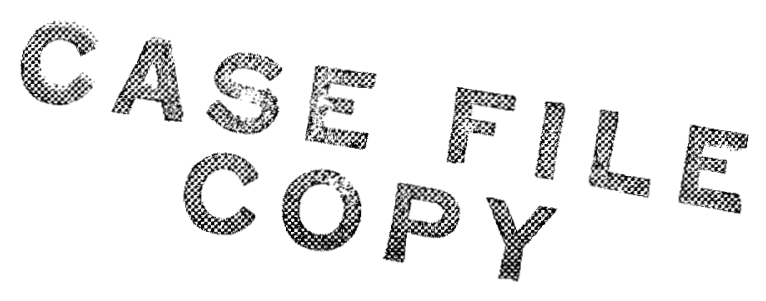

\title{
EXHAUST CHARACTERISTICS OF A MEGAWATT NITROGEN MPD-ARC THRUSTER
}

by Charles J. Michels and Donald R. Sigman

Lewis Research Center

Cleveland, Ohio

- TECHNICAL PAPER proposed for presentation at Eighth Electric Propulsion Conference sponsored by the American Institute of Aeronautics and Astronautics Stanford, California, August 31-September 2, 1970 
EXHAUST CHARACTERISTICS OF A MEGAWATT NITROGEN MPD-ARC THRUSTER

by Charles J. Michels and Donald R. Sigman

Lewis Research Center

Cleveland, Ohio

TECHNICAL PAPER proposed for presentation at Eighth Electric Propulsion Conference sponsored by the American Institute of Aeronautics and Astronautics Stanford, California, August 31-September 2, 1970 


\title{
EXHAUST CHARACTERISTICS OF A MEGAWATT NITROGEN MPD-ARC THRUSTER
}

\author{
Charles J. Michels and Donald R. Sigman \\ Lewis Research Center \\ National Aeronautics and Space Administration \\ Cleveland, Ohịo
}

\section{Abstract}

The number density $\left(\mathrm{n}_{\mathrm{e}}\right)$ electron temperature $\left(\mathrm{T}_{\mathrm{e}}\right)$, and velocity of the exhaust of a single pulse thruster were experimentally determined for various applied axial magnetic fields $(0,1.0$, and $2.0 \mathrm{~T})$. At an axial station $0.2 \mathrm{~m}$ from the anode, the no-field exhaust profile is approximately constant up to $4.0 \mathrm{~cm}$ from the centerline, $\mathrm{n}_{\mathrm{e}}=1.0 \times 10^{21} \mathrm{p} / \mathrm{m}^{3}, \mathrm{~T}_{\mathrm{e}}=7.2 \mathrm{eV}$. At 1.0 and $2.0 \mathrm{~T}$, centerline $\mathrm{n}_{\mathrm{e}}<10^{21} \mathrm{p} / \mathrm{m}^{3}$ and the $\mathrm{n}_{\mathrm{e}}$ raises to a maximum of $1.0 \times 10^{21} \mathrm{p} / \mathrm{m}^{3}$ and $0.6 \times 10^{21}$ $\mathrm{p} / \mathrm{m}^{3}$ respectively at a radius of $2 \mathrm{~cm}$. Corresponding velocities $\left(0.2 \rightarrow 0.8 \times 10^{4} \mathrm{~m} / \mathrm{sec}\right)$ were measured and are discussed.

\section{Introduction}

This report describes the experimental investigation of some of the exhaust characteristic s of a single-shot, pulsed, MPD-ARC thruster. The high power level (MW) of the experiment provided an exhaust plasma density which was great enough to allow diagno sis using Thomson scattering of pulsed laser light. This technique gives number density and electron temperature of the exhaust without the complication of other auxiliary mea surements or assumptions. As well, the excellent time and space resolution of this technique allow for obtaining exhaust profiles (spatial and temporal).

The exhaust characteristics of the MPD-ARC thruster (number density, electron temperature, and velocity) reported herein are an essential part of the basic knowledge required:

(1) For fea sibility as a thruster,

(2) For feasibility as a source for a plasma blowdown tunnel, and

(3) For understanding the physics of the exhaust of arcs employing auxiliary magnetic fields.

Pulsed, megawatt level, MPD-ARC investigations have been reported by Jahn et al. (1) for the self field case, the thruster being powered by a delay-line capacitor bank. The investigation at Lewis Research Center of pulsed, megawatt level, MPD-ARCs has been initially reported by Michels $(2,3)$. These reports $(2,3)$ describe terminal characteristics for the auxiliary magnetic field case, the thruster being powered by a crowbarred capacitor bank. The arc current decays with time and with this type power source. A portion of the detailed investigation described by Jahn et al. (1) gives the number density and temperature for one self field case. The se are obtained with a local probe in direct contact with the plasma. Herein, plasma diagno sis through
Thomson scattering is used as an independent and direct method of obtaining number density and electron temperature for various values of auxiliary magnetic field. The technique of determining number density and electron temperature from Thomson scattering of the beam of a Q-spoiled ruby laser is now well established $(4,5)$. The combination of low electron temperature (a few electron volts) and low number density (approximately $10^{20}$ particles per cubic meter) have been the criterion that determined the simple, yet judiciously designed, two-channel, $90^{\circ}$ scattering system used in this experiment.

Apparatus

\section{Capacitor Bank}

The plasma source was energized by a 10 kilojoule bank. The equivalent circuit of the bank, crowbar switch, and the source is shown in Fig. 1. After the bank switch was closed, arc current was allowed to develop to its peak current. This takes $21 \mu$ sec. Then the crowbar switch was closed, forcing the arc current to decay monotonically with time. The $L / R$ decay time ranged from 250 to $350 \mu \mathrm{sec}$, depending on arc resistance. This allowed an almost linear decay of arc current for about $100 \mu \mathrm{sec}$ after crowbarring and it is during this period that the data was gathered.

\section{Plasma Accelerator}

A photograph of the plasma accelerator is shown in Fig. 2. The arc chamber is hidden from view at the center of the toroidal dewar for the superconducting magnet. The magnet is used to supply the auxiliary magnetic field for the accelerator. Plasma flows to the left from the accelerator into an evacuated glassware sy stem.

Prior to operating the source, the magnet dewar was filled with liquid helium, and after it became cold the magnet wire became superconducting. Then the magnet was charged to a given magnetic field setting ( 0 to 2.2 $T)$ and maintained at that condition for the testing period. The capacitor bank was charged next. It was not switched until propellant had properly filled the arc chamber $(650 \mu \mathrm{sec})$. For operational convenience the cathode was not preheated for the experiments to be described here.

Nitrogen propellant is introduced into the arc chamber by a high-speed gas valve that is actuated by an electromagnetic system. All tests were run at $0.007 \mathrm{~kg} / \mathrm{sec}$ nitrogen. The transient, cold flow, gas pressure in the arc chamber was measured by a piezoelectric pressure pickup in a previous experiment. 
Using that pressure and orifice equations for steady flow, the mass flow rate for all the tests of this report were calculated. From the transient pressure records it was found that stable flow occurred after $650 \mu \mathrm{sec}$ and the arc was started at that time. The arc was formed between the cathode and anode ring. A transient plasma flows for a few hundred microseconds into the evacuated region to the left of Fig. 2.

A cross-sectional view of the arc chamber is shown in Fig. 3. An iron filings map of the magnetic field is also shown. The cathode is a tungsten ribbon measuring $1 \mathrm{~cm}$ wide, $2 \mathrm{~cm}$ long, and $1 \mathrm{~mm}$ thick. The anode is a $4.2 \mathrm{~cm}$ inside diameter copper ring.

A sequence controller controls gas puff injection, delay for gas distribution, bank switch closure, crowbar switch closure, and then data gathering "start" and "stop" times.

\section{Instrumentation}

"Thomson Scattering". - Fig. 4 gives the schematic of the laser diagnostic equipment and its relationship to the plasma test section. The laser was a $Q$-switched ruby with 2 joules output. The portion of the light measured was that which was scattered in a direction normal to the plane of polarization of the laser beam (i.e., $90^{\circ}$ Thomson scattering). To minimize the stray light entering the detection system a series of light stops were placed along the path of the incoming beam and two light dumps were used. One light dump (no. 1) serves as a dump for the main beam, and the other (no. 2) serves as a black background for the scattered light detection system. The Doppler-shifted scattered light was analyzed through the use of a two-channel interference filter system similar to that of Patrick. (6) The photomultipliers are EMI $9558 \mathrm{~B}^{\prime} \mathrm{s}$. Each channel has a filter holder containing up to seven filters which can be easily changed. In the experiment the scattering parameter $\propto\left[=\lambda /\left(4 \pi \lambda_{\mathrm{D}} \sin \theta / 2\right)\right]$ is much less than one $(\approx 0.1) . \quad \lambda$ is the laser wavelength and $\lambda_{D}$ the Debye distance. Theoretically then, if a Maxwellian electron velocity distribution is assumed, single-shot data from two filters with different peak wavelengths is sufficient to determine the temperature. Using the available transmission curves for the interference filters the fraction of scattered light passed by each filter was calculated as a function of electron temperature. The ratio of these fractions for filters with peak wavelengths of $695.0 \mathrm{~nm}$ and $697.1 \mathrm{~nm}$ is given in Fig. 5 . In taking data the ratios were computed for each shot and then a series of five ratios was averaged before determining the temperature from Fig. 5 .

Temperatures could also be determined by using just one of the channels. In this case ten shot averages were taken for a series of six filters ranging in peak wavelength from $694.3 \mathrm{~nm}$ to $697.8 \mathrm{~nm}$. A best fit was then made of the theoretical curves to determine the temperature. Fig. 6 shows a comparison of theoretical and a typical experimental profile. It was found that temperatures obtained through the two methods agreed within the limits set by nonreproducibility of the discharge and other statistical factors.
Most of the data herein was taken using the twochannel method, since fewer shots were needed. There was also the added advantage that signal ratios taken from the same laser shot and plasma discharge were more accurate than tho se derived from two separate shots.

The system was calibrated for density by measuring the Rayleigh scattered light when the test section was filled with nitrogen at a few millimeters pressure. The shot to shot variation in the calibration signals was less than \pm 10 percent.

For scattering from the plasma, shot to shot variations ranged from \pm 10 to \pm 30 percent. Examination of other diagnostics such as light emitted over the plasma and Faraday cup signals indicates that this shot to shot variation in Thomson scattering can be explained by the nonreproducibility of the discharge.

The lower limit in density which could be accurately determined in this experiment was about $0.5 \times 10^{20} \mathrm{~m}^{-3}$. This limit occurs because of the noise on the photomultiplier signal resulting from the light emitted by the plasma. This limit can obviously be reduced by the use of a higher powered laser. Fig. 7 shows typical twochannel scattered light signals.

"Faraday Cup Probe". - A Faraday cup probe was used to collect ions from the streaming plasma simultaneous with scattered light data gathering. It was biased with a $45 \mathrm{~V}$ battery to repel electrons from the cup. The probe face was kept $10 \mathrm{~cm}$ downstream from the scattering measuring station so as not to introduce stray light signals in the scattering chamber. The probe could be positioned to be on the same duct radius as the scattering measurement. Pinholes could be changed on the probe face $(0.0002 \mathrm{~m}$ dia. or $0.00074 \mathrm{~m}$ dia.). The probe system was kept electrically floating. Instrument isolation amplifiers with excellent common mode rejection were employed. In order to obtain isolation and good common mode rejection instrument response time was compromised at $15 \mu \mathrm{sec}$ rise time. Thus the leading edge and fine detail of the cup signal were not available in this experiment. Since collected ion current is proportional to area, a check was made to insure that this was the case by changing hole size. This proved to be linear.

\section{Results and Discussion}

The value of a direct method of determining number density through Thomson scattering was demonstrated clearly in the early stages of this experiment. It was found that minor changes in the insulator design near the cathode in the chamber (all other dimensions and materials remaining the same) seriously affected the exhaust number density. Factors of two to three increase in number density were obtained by fully insulating the cathode supports. This forced the discharge to be initiated and seated at the cathode ribbon. In earlier designs, a very minor arcing damage was noted on the cathode supports. This probably occurred only briefly in random arc initiations. In this report, only the data for the most improved version will be described. 
The precise temporal and spatial resolution of the Thomson scattering technique identified another feature of the exhaust. Shot to shot variations in number density and temperature were serious. The variations in the manner of initiation and development of the arc thus were observable as exhaust variations. The data presented is the mean value of at least five shots for each condition.

The exhaust flowed from the source into a $15 \mathrm{~cm}$ diameter evacuated glassware duct. A detailed examination of the exhaust was undertaken at a station $20 \mathrm{~cm}$ downstream from the anode face. The number density and electron temperature profiles were measured at the station for various auxiliary magnetic field cases $(0$, 1.0 , and $2.0 \mathrm{~T}$ ). The results are shown in Fig. 8 for the case where peak arc-current for each shot is $\mathbf{1 3 . 4}$ $\mathrm{kA}$. All shots had the same mass flow rate $(0.007 \mathrm{~kg} / \mathrm{sec}$ $\mathrm{N}_{2}$ ), and the same gas settling time of 650 microseconds. The data was taken about 20 micro seconds after the plasma light front had reached the measuring station. This time was cho sen so that initial transient effects would be small and the measurement would be made in the streaming plasma portion of the flow.

The time history of the plasma light passing the measuring station has a general shape shown below in Fig. 9. Shot to shot this shape varies, sometimes the pedestal portion is distinct, at other times it is part of the smoothly decaying tailoff portion. Generalily, the spike portion has less number density by at least an order of magntiude. The pedestal has $\mathrm{N}_{e}$ values in the range of $10^{20}-10^{21} \mathrm{p} / \mathrm{m}^{3}$ and the tail portion has lower and time-decaying values. Moving the measurement time later (to $60-70 \mu \mathrm{sec}$ on the sketch) quite often showed factors of two reduction in number density. This is to be expected since during that corresponding time the arc power is reducing also by like factors due to the decay in arc current.

With these general characteristics understood, the data of Fig. 8 can now be discussed. For the case of no auxiliary field, the number density is $1.0 \times 10^{21} \mathrm{p} / \mathrm{m}^{3}$. The density profile was nearly constant from duct centerline to $4 \mathrm{~cm}$ radius. The electron temperature falls linearly from a centerline value of $7.3 \mathrm{eV}$ to $3.5 \mathrm{eV}$ $(4 \mathrm{~cm})$. The arc power was $2.3 \mathrm{MW}$ at $36 \mu \mathrm{sec}$ after the arc was initiated. That is $15 \mu$ secs after the crowbar time. The number density profile was much different for the cases where an auxiliary magnetic field is employed. Over an order of magnitude reduction in density occurs on centerline for both the 1.0 and $2.0 \mathrm{~T}$ cases. The peak density occurs at a radius of $2.0 \mathrm{~cm}$. At the $2 \mathrm{~cm}$ radius for the $1.0 \mathrm{~T}$ case, the number density was still about $1.0 \times 10^{21} \mathrm{p} / \mathrm{m}^{3}$ but for the $2.0 \mathrm{~T}$ case it reduced to $0.6 \times 10^{21} \mathrm{p} / \mathrm{m}^{3}$. For the $2.0 \mathrm{~T}$ case, the arc power was $9.5 \mathrm{MW}$, at $36 \mu \mathrm{sec}$ after the arc was initiated, over four times greater than the "no field" case. This power increase was not manifest by number density increase, nor electron temperature increases from the "no field" case, in fact, the density reduced! With these facts, the next logical exhaust characteristic, velocity, was measured.

The time of arrival of the light front at the measuring station was used to determine the velocity, VLITE, shown in Fig. 8. This is an indicator of light front behavior only and not necessarily ion velocity after the front has passed. For the "no field" and $1.0 \mathrm{~T}$ cases, V IITE were alike, within measurement error at about $0.4 \times 10^{4} \mathrm{~m} / \mathrm{sec}$. The velocity for the $2.0 \mathrm{~T}$ case was 10 percent greater. This would not be a great enough increase for the power increase to be explained as increased ștreaming energy.

An attempt was made to obtain ion velocity through the use of a biased Faraday cup. At the $13.4 \mathrm{kA}$ peak current case, only one condition was examined successfully. This was because at higher power levels the ratio of the common mode signal (to the measurement signal) could not be reduced enough. From the one successful cup measurement at $13.4 \mathrm{kA}$ and the corresponding number density, the ion velocity, $V_{i}$, was found to be $0.58 \times 10^{4} \mathrm{~m} / \mathrm{sec}$. This prompted investigation of a lower power level regime where the cup could be used successfully.

At the lower power regime (7.4 kA peak arc current) the measurements were made at $\mathrm{r}=2 \mathrm{~cm}$ (where $\mathrm{N}_{e}$ is the greatest value). The data are shown for the $7.4 \mathrm{kA}$ peak current case in Fig. 10 and the $13.4 \mathrm{kA}$ data is included for comparison. The number densities were lower for the $7.4 \mathrm{kA}$ case, as are the front velocities. Ion velocities, from the Faraday cup measurements, showed a six-fold increase as the field is increased from 0 to $2 T$. Thus, at this power level, the ion velocity increase comes closer to being proportionate to the observed power increase. Again, as for the $13.4 \mathrm{kA}$ cases, it was found that $V_{\text {LITE }}$ increased slightly with applied magnetic field. Thus VIITE is only an indicator of front arrival effects and not the streaming ion flow component of the exhaust.

The product $\mathrm{N}_{e} \mathrm{~V}_{\mathrm{i}}$ should indicate the exhaust momentum for that station and time. This product, when plotted versus applied magnetic field (see Fig. 11) peaks at about $1.0 \mathrm{~T}$ for the data of Fig. 10.

The product $\mathrm{N}_{\mathrm{e}} \mathrm{V}_{\mathrm{i}}^{2}$ should be proportional to dynamic stream pressure. For the data of Fig. 10, $\mathrm{N}_{\mathrm{e}} \mathrm{V}_{\mathrm{i}}{ }^{2}$ is almost linearly increasing with applied magnetic field. It is planned, in the near future, to examine, with an independent measurement of dynamic pressure, if the pressures obtained agree with the Faraday cup derived pressure calculations.

\section{Concluding Remarks}

The number density and electron temperature of the exhaust of a pulsed megawatt MPD-ARC plasma thruster were determined for two different peak arc-current cases $(13.4 \mathrm{kA}$ and $7.4 \mathrm{kA}$ ) for various values of auxiliary magnetic field $(0$. to $2.0 \mathrm{~T})$. The radial profile of the exhaust was obtained for a position $20 \mathrm{~cm}$ downstream from the anode face. For the $13.4 \mathrm{kA}$ case, with no auxiliary field, the centerline number density was $1 \times 10^{21} \mathrm{p} / \mathrm{m}^{3}$ and was relatively flat out to $4.0 \mathrm{~cm}$ radius. For the applied field cases the centerline number density is reduced to below $10^{20} \mathrm{p} / \mathrm{m}^{3}$ and peaks at $0.02 \mathrm{~m}$ radius. At the $2 \mathrm{~cm}$ radius location, for the 1.0 $\mathrm{T}$ case the number density is still about 
$1.0 \times 10^{21} \mathrm{p} / \mathrm{m}^{3}$ but as field is increased above this point number density reduces. At $2.0 \mathrm{~T}$ the number density is down to $0.6 \times 10^{21} \mathrm{p} / \mathrm{m}^{3}$. An electron temperature range from 7.3 to $3.0 \mathrm{eV}$ was noted. Using the Thomson scattering technique is a very powerful aid in examining high density exhaust. It gives local $\mathrm{N}_{\mathbf{e}}$ and $\mathrm{T}_{\mathbf{e}}$ directly without auxiliary methods or assumptions and with excellent temporal and spatial resolution without perturbing the plasma.

The same degree of confidence cannot be applied to the velocity measurements discussed herein. These suffer the usual "probe-in-plasma" uncertainties. The Faraday cup derived velocities determined for the $7.4 \mathrm{kA}$ range from 0.1 to $0.68 \times 10^{4} \mathrm{~m} / \mathrm{sec}$. The probe perturbs the plasma an unknown degree, has the attendant particle gathering problems, and cannot be used in very high power, extended pulse duration, exhausts.

The temperature measurements for the "no-field" and field cases show that increasing arc power through the aid of a passive externally applied, magnetic field is not manifest by increased electron heating. Although not conclusive, but rather useful to suggesting the direction of further investigation, the lower powered part of this experiment has suggested that the increased power from the "no field" case tofield cases does manifest itself primarily in increased plasma streaming energy. More work needs to be done to verify this through another independent velocity measurement, over more stations and at higher power.

\section{Acknowledgement}

The assistance of $\mathrm{Mr}$. Ronald $\mathrm{R}$ Robson in providing instrumentation and operations angineering support is gratefully appreciated.

\section{References}

1. Jahn, R. G., Clark, K, E., Oberth, R. C., and Turchi, P. J., "Acceleration Patterns in QuasiSteady MPD Ares, " Paper 70-165, Jan. 1970, AIAA, New York, N. Y

2. Anon., "Plasmas and Magnetic Fields in Propulsion and Power Research, " SP-226, 1970, NASA, Washington, D:C:, pp. 21-22.

3. Michels, C. J., "Dynamic Current-Voltage Characteristics of a Megawatt MPD-ARC Thruster," Paper 70-164, Jan. 1970, AIAA, New York, N. Y.

4. Schwarz, S. E., "Studies on Optical Scattering as a Technique for Plasma Diagnostics, " Scientific Report 1, AFOSR-64-1143, May 1964, Quantum Flect. Lab., California Inst. Tech., Pasadena, Calif.

5. Evans, D. E. and Katzenstein, J., "Laser Light Scattering in Laboratory Plasmas, "Reports on Progress in Physics, Vol. 32, Pt. 1, 1969, pp. 207-271.
6. Patrick, R. M., "Thomson Scattering Measurements of Magnetic Annular Shock Tube Plasmas," Physics of Fluids, Vol. 8, No. 11, Nov. 1965, pp. 19851994. 


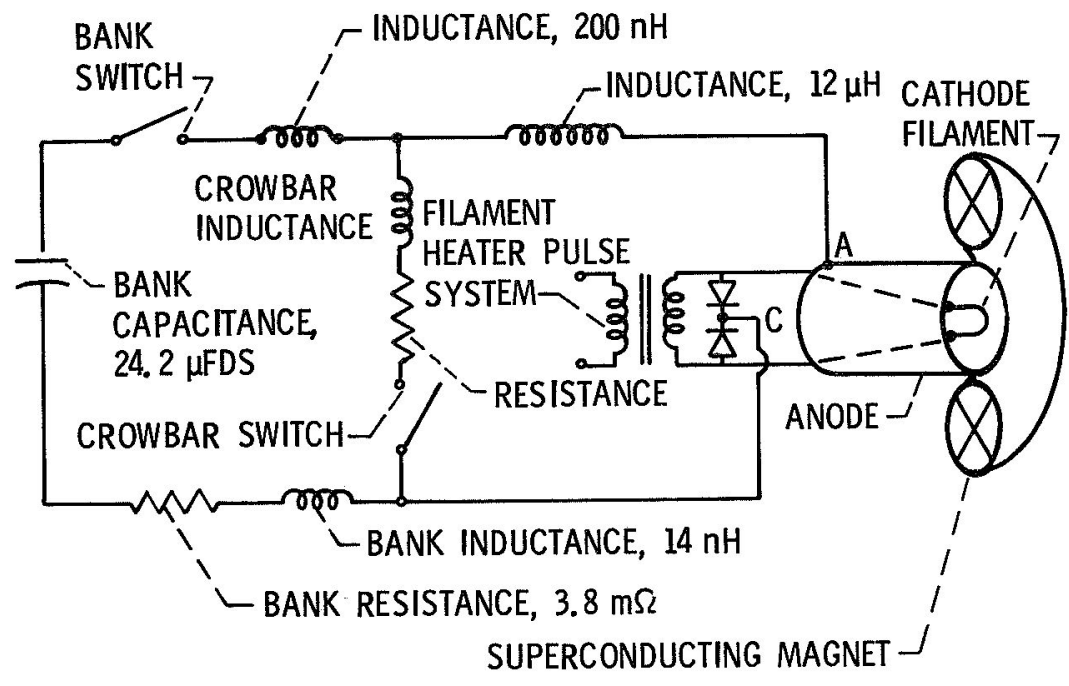

Figure 1. - Equivalent circuit.

CS-51546

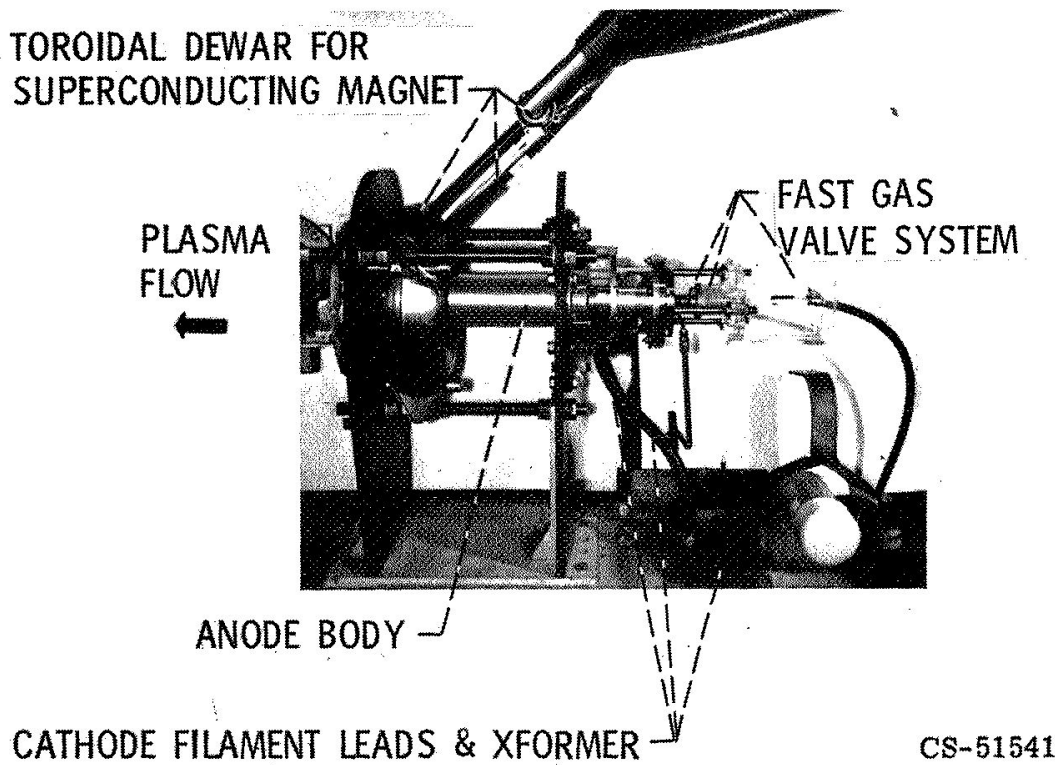

Figure 2. - Plasma accelerating system. 


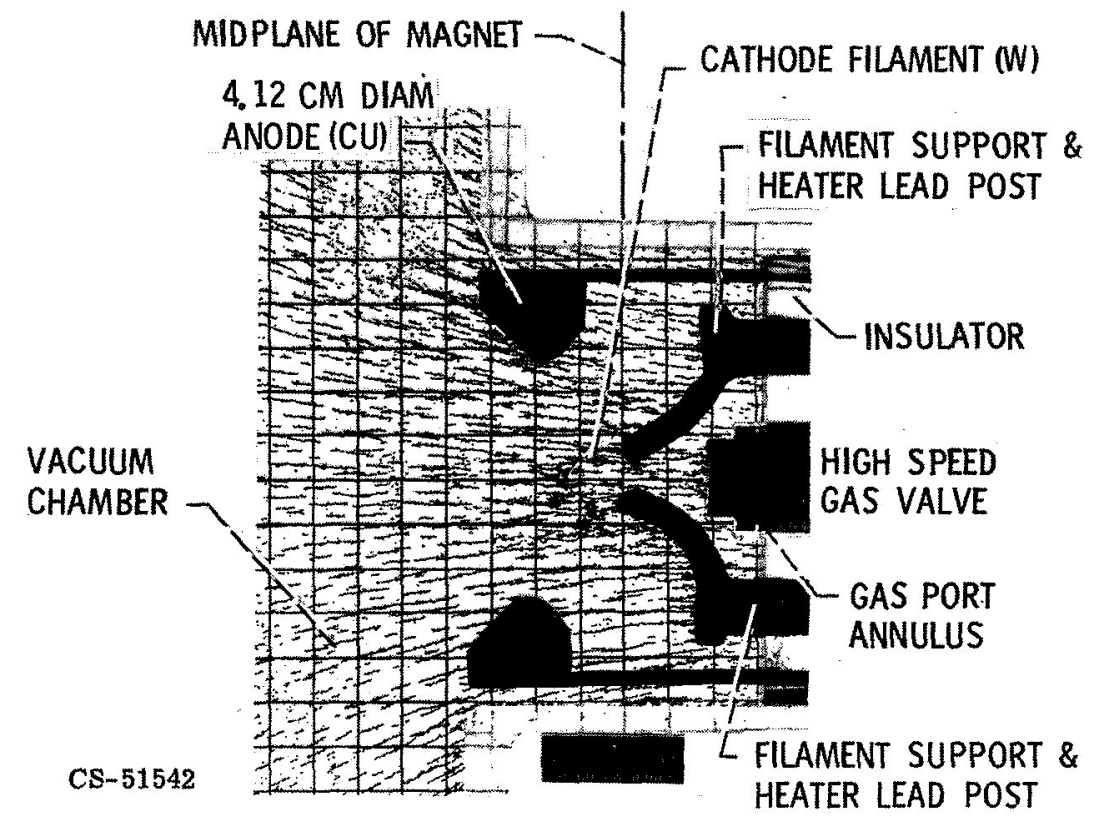

Figure 3. - Arc chamber. 


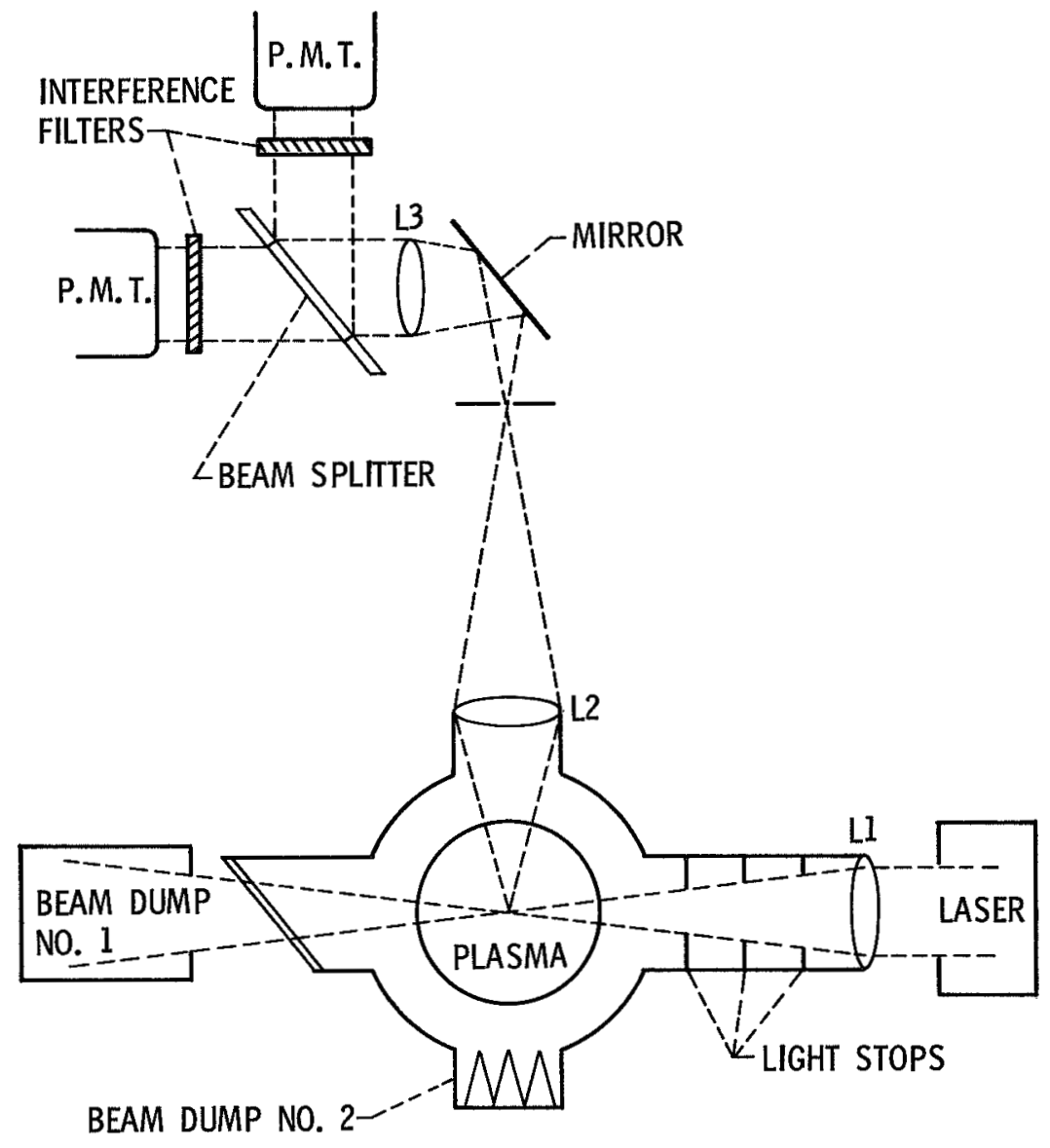

Figure 4. - Schematic of scattering diagnostic equipment. 


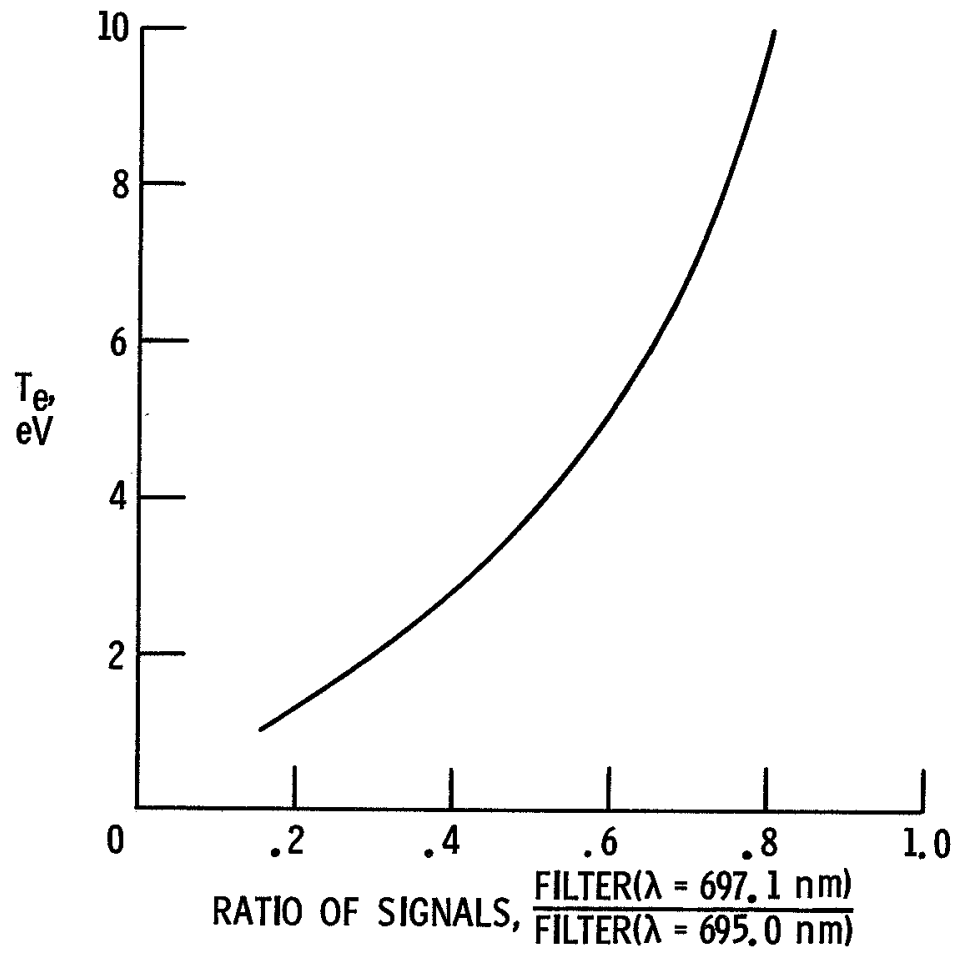

Figure 5. - Temperature vs signal ratio.

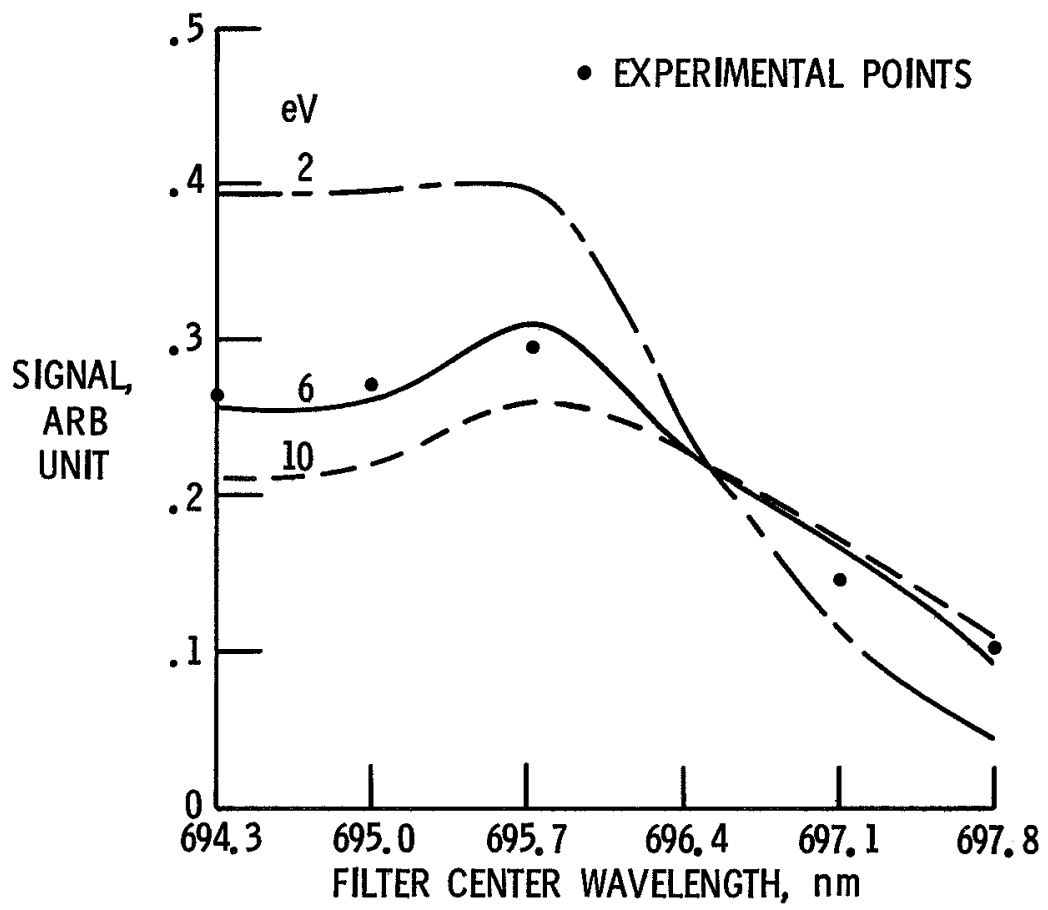

Figure 6. - Theoretical and experimental spectral profiles. $\mathrm{T}_{\mathrm{e}} \approx 6 \mathrm{eV}, \mathrm{n}_{\mathrm{e}} \approx 1 \times 10^{21} \mathrm{~m}^{-3}$. 


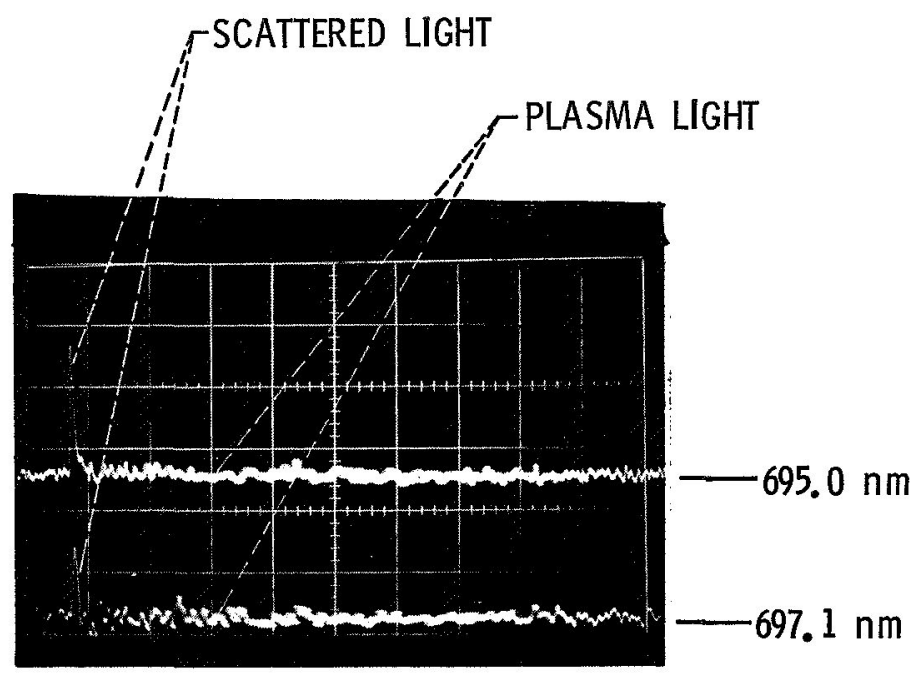

TIME $\rightarrow 0.5 \mu \mathrm{SEC} / \mathrm{CM}$

Figure 7. - Typical two-channel photomultiplier signals.

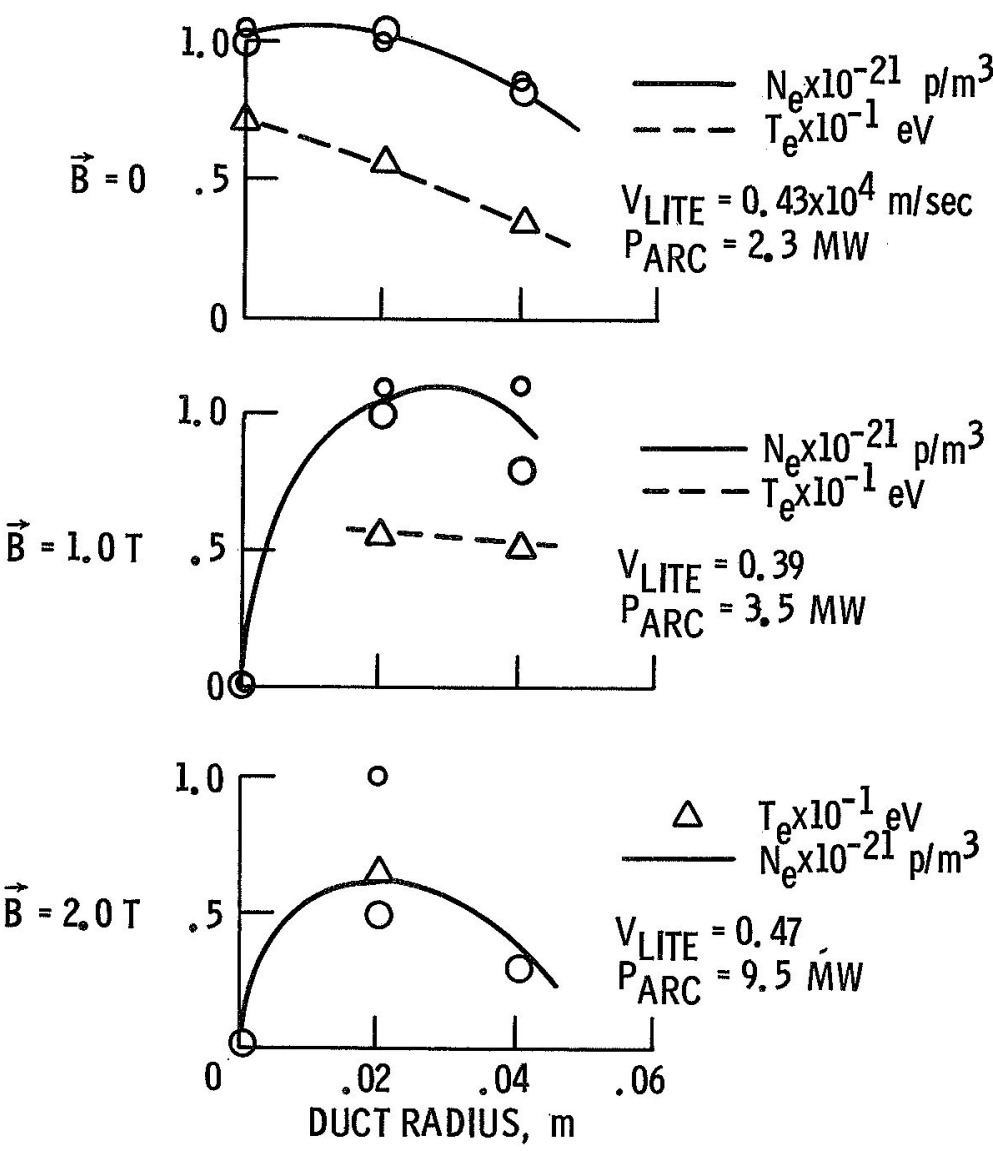

Figure 8. - Exhaust characteristics. 


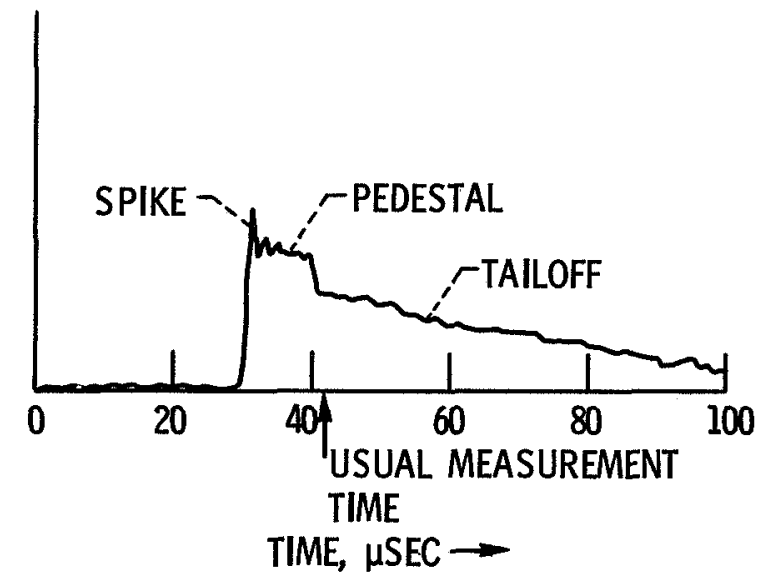

Figure 9. - Typical plasma light time history.
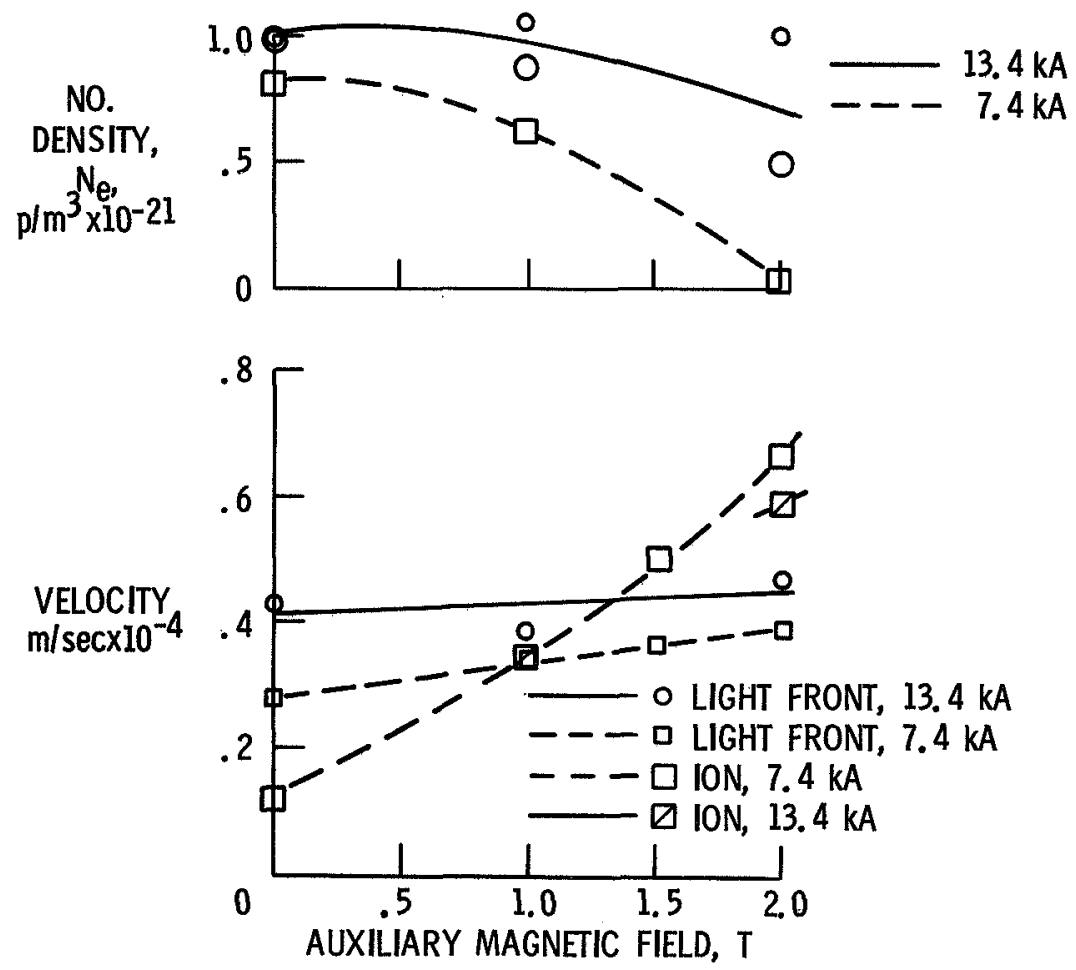

Figure 10. - Exhaust characteristics vs magnetic field at $r=0.02 \mathrm{~m}, z=0.2 \mathrm{~m}$. 
尔
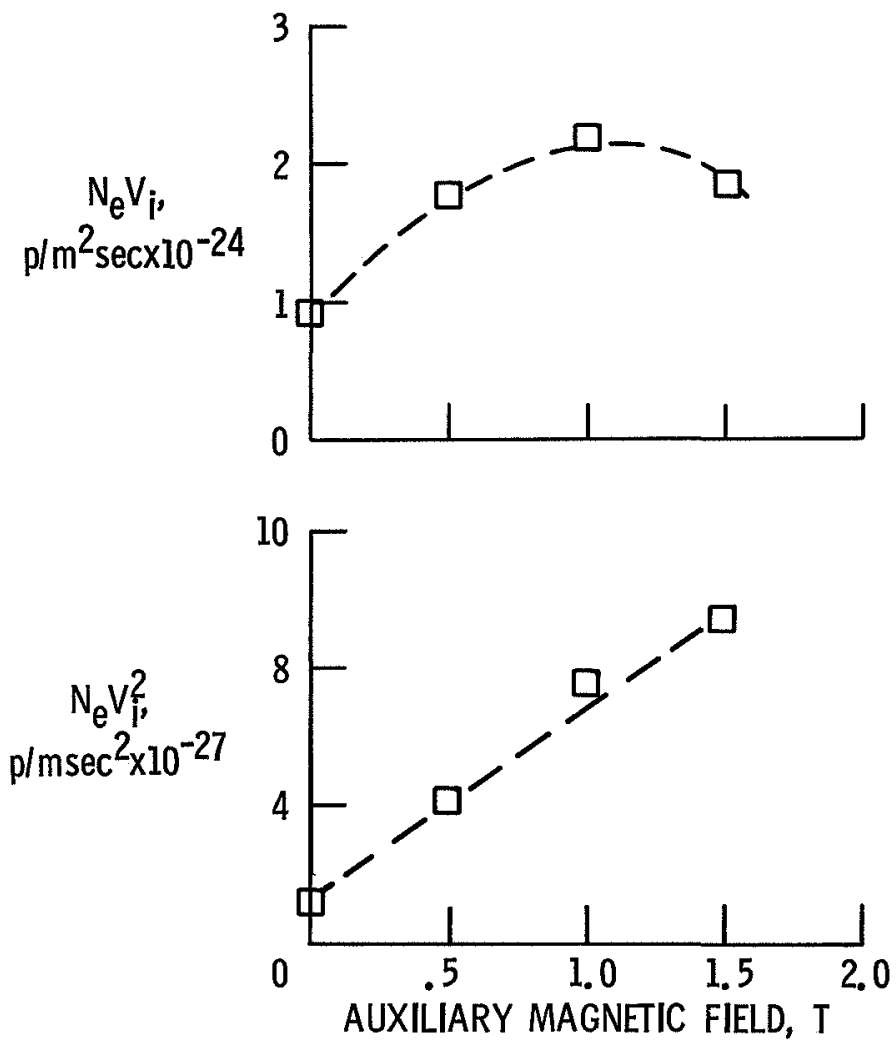

Figure 11. - Exhaust $\mathrm{N}_{e} \mathrm{~V}_{\mathrm{i}}$ and $\mathrm{N}_{\mathrm{e}} \mathrm{V}_{\mathrm{i}}^{2}$ vs magnetic field strength at $r=2 \mathrm{~cm}, z=20 \mathrm{~cm}, 7.4 \mathrm{kA}$. 